\title{
An insight into vertebral fractures
}

\author{
Robert Gunzburg • Marek Szpalski • \\ Max Aebi
}

Received: 2 February 2010/Published online: 3 March 2010

(c) Springer-Verlag 2010

This supplement to the European Spine Journal follows an international symposium held in Brussels and organized by the co-editors to this issue. It was not aimed to provide an exhaustive review of all types of fractures and their different treatments, but rather to provide a state of the art look onto several important aspects related to spinal trauma.

Vertebral fractures were discussed, with the exception of pathologic or osteoporotic fractures.

Injury classification was presented and the specific imaging modalities related to fractures of the spine were analyzed.

As for most conditions relating to the spine both a conservative and surgical approach can be proposed in the management of spinal fractures. The different segments of the spine, cervical-thoracic-lumbosacral, with their particular characteristics of mobility, stability and protection of neural structures, pose varying challenges to the clinician. Several aspects of these challenges are being debated here.

Both conservative and surgical treatment of spinal fractures can lead to complications of which some are looked into in depth: malunion and post-traumatic kyphosis.

With the ever increasing cost of medical care worldwide, we conclude by analyzing the financial implications of spinal trauma on society.

Conflict of interest statement None.
R. Gunzburg

MD, Assistant to the Editor-in-Chief

Eeuwfeestkliniek, Harmoniestraat 68,

2018 Antwerp, Belgium

M. Szpalski ( $\square)$

MD, Deputy Editor

21 Avenue Coghen, 1180 Brussels, Belgium

e-mail:mszp@skynet.be

M. Aebi

MD, Editor-in-Chief

Institute for Evaluative Research in Orthopaedic Surgery,

University of Bern, Stauffacherstrasse 78,

3014 Bern, Switzerland 